\title{
DEVELOPMENT OF JUMPING ABILITY AND ITS INFLUENCE ON THE PROFICIENCY OF ATTACK IN THE FEMALE VOLLEYBALL TEAM OF TALLINN UNIVERSITY IN THE 2012/2013 SEASON
}

\author{
Raini Stamm ${ }^{1}$, Meelis Stamm ${ }^{2}$, Sylvia Tammerik ${ }^{1}$ \\ ${ }^{1}$ Tallinn University, Institute of Health Sciences and Sports, Tallinn, Estonia \\ ${ }^{2}$ Tallinn University, Institute of Educational Sciences, Tallinn, Estonia
}

\begin{abstract}
The aim of this study was to improve the jump performance of the Tallinn University female volleyball team and to examine the relation between the development of jump performance and attack performance.

The study examined 10 female Premier League volleyball players, aged $21.3 \pm 2.4$ years and with $11.3 \pm 2.5$ years of experience from Tallinn University during the 2012/2013 season. Anthropometric measuring (height, weight and 9 circumferences), jump performance testing and attack efficiency recording were carried on all the players. After testing and analysis, the players participated in A.V. Belyayev and L.V. Bulykina's jump performance training programme, which is developed exclusively for volleyball players [1]. After the 54-day training programme, anthropometric measuring, jump performance testing and attack efficiency recording were carried out again to examine the results of the programme.

The study fulfilled its objective. As a result of the jump performance training programme, the average results improved by $4 \mathrm{~cm}$ for the standing jump and reach and by $5 \mathrm{~cm}$ for the running jump and reach. The changes were statistically significant. Evaluation of the attack efficiency before and after the programme showed that attack efficiency, attack proficiency and points scored per game had also improved. However, these changes were statistically insignificant compared to the team's average data. The main differences between anthropometric measurements before and after the jumping performance programme were found in weight (before $71.7 \mathrm{~kg}$ and after $70.2 \mathrm{~kg}$ ); the mean waist
\end{abstract}


circumference decreased by $2 \mathrm{~cm}$ and the mean hips circumference by $0.9 \mathrm{~cm}$. A check-up by the t-test showed that the changes in the mean anthropometric measurements of the team were statistically insignificant.

Keywords: female volleyballers, anthropometry, jumping ability, attacking efficency.

\section{INTRODUCTION}

As the majority of volleyball technical elements (attack, feint, block, set, serve) are performed from the jump, the height and reach of the jump are some of the most essential factors in the achievement of success. Many authors writing on volleyball have emphasised the significance of the jump reach in the game $[2,3]$.

The current study concentrates on the question whether, after improvement of jumping performance, the player will also become more proficient at attack. When jumping higher, the player is in the air for a longer time and has more time for deciding where to direct the spike and can direct it to the top of the opponent's block or even over it [6].

\section{SUBJECTS OF THE STUDY}

The sample under study consisted of 10 volleyball players whose average year of birth was 1991 and who had practised volleyball for 11.3 years on average. In the 2012/2013 season, all of them belonged to the Premier League female team of Tallinn University. The sample consisted of two middle blockers, three outside attackers, two opposite attackers and three libero players.

\section{METHODS}

All the subjects underwent an anthropometric study where their height, weight, upper chest circumference, waist circumference, hips circumference, upper leg circumference, upper and lower circumference of lower leg, arm circumference, arm circumference flexed and tensed, wrist circumference and hand reach according to the method of Martin were measured. All the measurements were taken by the same person. To measure the weight, electronic scales $( \pm 0.5 \mathrm{~kg})$ were used; for the length measurements, a measuring stick and a metal measuring tape were used. To measure the circumferences also a metal measuring tape was used. Measurements were taken with the precision of $\pm 0.5 \mathrm{~cm}$. 
Thereafter, the subjects took physical abilities tests where the reach of the standing and the running jump were measured. The tests measure the explosive strength of the player's leg muscles.

The standing jump and reach test [8] measures the height of the standing jump and the explosive strength of the leg muscles. First, the player's hand reach was measured. For that, the subject stood with her side (right-handed subjects with the right side, left handed subjects with the left side) against the wall and stretched her hand upwards as high as she could. The height from the ground to the fingertips was measured. Then, the subject performed a vertical jump upwards, from a half-squat, without a preparatory jump, touching the measuring table as high as she could (right-handed subjects with the right hand, left-handed subjects with the left hand). The subject took three attempts of which the best one was taken into account. By fixing the result of the jump and subtracting from it the player's hand reach, we got the player's standing jump height.

The running jump and reach test [8] measures the height of the running jump and leg muscles explosive strength. The subject stood five steps away from the measuring table that was attached to a basketball board. Then, from a run-up, she performed a vertical jump upwards, touching the measuring table as high as she could (right-handed subjects with the right, left-handed subjects with the left hand). The subject took three attempts of which the best one was taken into account. By fixing the result of the jump and subtracting from it the player's hand reach, we got the player's running jump height.

The study of proficiency of spike was carried out using the statistics program Volleyball Software, Stats version 6.3 [7]. Statistics computed by this program are required by the Estonian Volleyball Association for analysis of each game of the Women's Championship League. Statistical analysis is performed by people trained for it. The statistical program shows the performance of each element of the game by each individual player. In this study, the authors concentrated on the proficiency of spike. The program shows the number of sets performed by an individual player or the number of opportunities to perform an attack. Out of them, mistaken attacks when the ball hits the net or goes out of bounds and successful attacks that yield a point are shown separately. In the study, the authors calculated the percentages of efficiency and proficiency according to the following formulas: 


$$
\begin{gathered}
\text { Efficiency }=\frac{\text { successful attacks }}{\text { totalnumberof attacks }} \times 100 \\
\text { Proficiency }=\frac{\text { successful attacks }- \text { mistaken attacks }}{\text { total number of attacks }} \times 100
\end{gathered}
$$

To assess the proficiency of spike, the authors observed six games that had been played before the jumping ability development programme and six games that were played against the same opponents after participating in the jumping ability programme. For the results to be well comparable, the same opponents were chosen for both periods of assessment.

After the testing the subjects participated in the jumping ability training programme. This is a 54-day programme specially developed for volleyball players. The programme has been created at the Russian University of Physical Education, Sport and Tourism by Prof. A. V. Belyayev PhD and Assoc. Prof. L. V. Bulykina PhD [1].

After participating in the jumping performance programme, the subjects took the same complex of tests where their anthropometric measurements were taken, the results of standing and running jump and reach were measured, and proficiency of attack in the following six games against the same opponents was calculated.

\section{RESULTS}

The players' mean age was 21.3 years $(S D=2.36)$ - the youngest player was 19 and the oldest 27 years old. Their mean experience in volleyball was 11.3 years $(\mathrm{SD}=2.50)$.

Anthropometric measurements were taken both before and after the jumping ability programme. A total of 11 body measurements were taken. The mean weight of the female team of Tallinn University before taking the jumping ability development programme was $71.7 \mathrm{~kg}(\mathrm{SD}=7.15)$ and after it $70.2 \mathrm{~kg}$ $(\mathrm{SD}=6.58)$. The team's mean height before the programme was $176.3 \mathrm{~cm}$ $(\mathrm{SD}=4.76)$ and after it $176.6 \mathrm{~cm}(\mathrm{SD}=4.55)$.

The mean upper chest circumference before the programme was $91.2 \mathrm{~cm}$ $(\mathrm{SD}=5.07)$. After the programme, it was $91 \mathrm{~cm}(\mathrm{SD}=5.29)$. Considering the team's arithmetic means, after the jumping ability development programme, the waist circumference diminished by $2 \mathrm{~cm}$. During the first measurements, the result was $74.9 \mathrm{~cm}(\mathrm{SD}=4.75)$ and the second measurements, $72.9 \mathrm{~cm}$ 
$(S D=3.31)$. The arithmetic mean hips circumference during the first measurement was $103.6 \mathrm{~cm}(\mathrm{SD}=5.21)$. During the second measurement, the result was nearly $1 \mathrm{~cm}$ smaller $-102.7 \mathrm{~cm}(\mathrm{SD}=5.44)$. Before the jumping ability development programme, the mean upper leg circumference of the team was $60.3 \mathrm{~cm}$ $(\mathrm{SD}=3.50)$; after the programme it was $60 \mathrm{~cm}(\mathrm{SD}=3.92)$. The arithmetic mean upper circumference of the lower leg during the first measurement was $37.6 \mathrm{~cm}(\mathrm{SD}=1.71)$. During the second measurement, the result was the same $-37.6 \mathrm{~cm}(\mathrm{SD}=1.35)$. Before the jumping ability development programme, the arithmetic mean lower leg circumference was $23.9 \mathrm{~cm}(\mathrm{SD}=0.74)$ and after it $24.1 \mathrm{~cm}(\mathrm{SD}=0.88)$. The means of the flexed and tensed arm circumference remained exactly the same during the first and the second measurements. The result was $29.6 \mathrm{~cm}(\mathrm{SD}=1.17)$. Before the jumping ability development programme, the arithmetic mean arm circumference was $28.6 \mathrm{~cm}(\mathrm{SD}=1.43)$ and after it $28.4 \mathrm{~cm}(\mathrm{SD}=1.43)$. The last measurement taken was wrist circumference. Its mean value did not change between the first and the second measuring periods. The result was $16.4 \mathrm{~cm}(\mathrm{SD}=0.52)$.

The first and the second results of weight, hips circumference and waist circumference were assessed by the t-test. The results did not differ statistically significantly (see Table 1).

The individual jumping performance of all the members of the Tallinn University female volleyball team improved after taking the one-and-a-half-month jumping ability development programme.

The mean result of the standing jump and reach test improved by $4 \mathrm{~cm}$ $(\mathrm{SD}=1.57)$.

A comparison of the running jump and reach test results before and after the jumping ability development programme showed an average improvement by $5 \mathrm{~cm}(\mathrm{SD}=2.41)$.

An essential factor in volleyball is not only how high the player can jump from the floor, but also the range of attack, i.e. from how high the player can attack (see Table 2). In the female volleyball team of Tallinn University, the players who could attack from the highest position were ST and SO. After the jumping ability development programme, both players' standing attack range was $2.85 \mathrm{~m}$. The mean of the team after the jumping ability development programme was $2.77 \mathrm{~m}$. The libero players MP2 and TT had the lowest range of standing attack with the result of $2.70 \mathrm{~m}$. This is $7 \mathrm{~cm}$ less than the team's mean (see Table 2). 


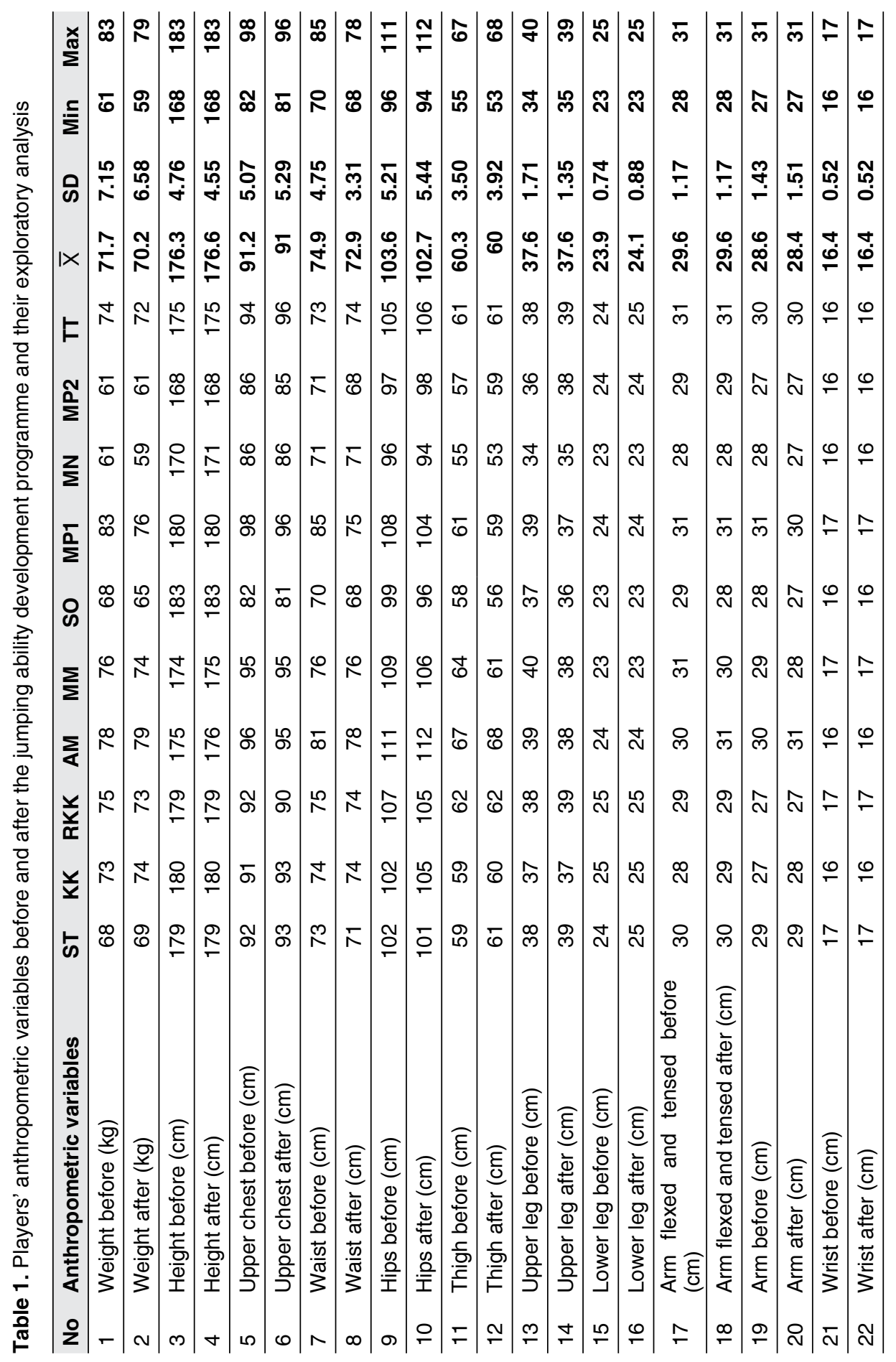




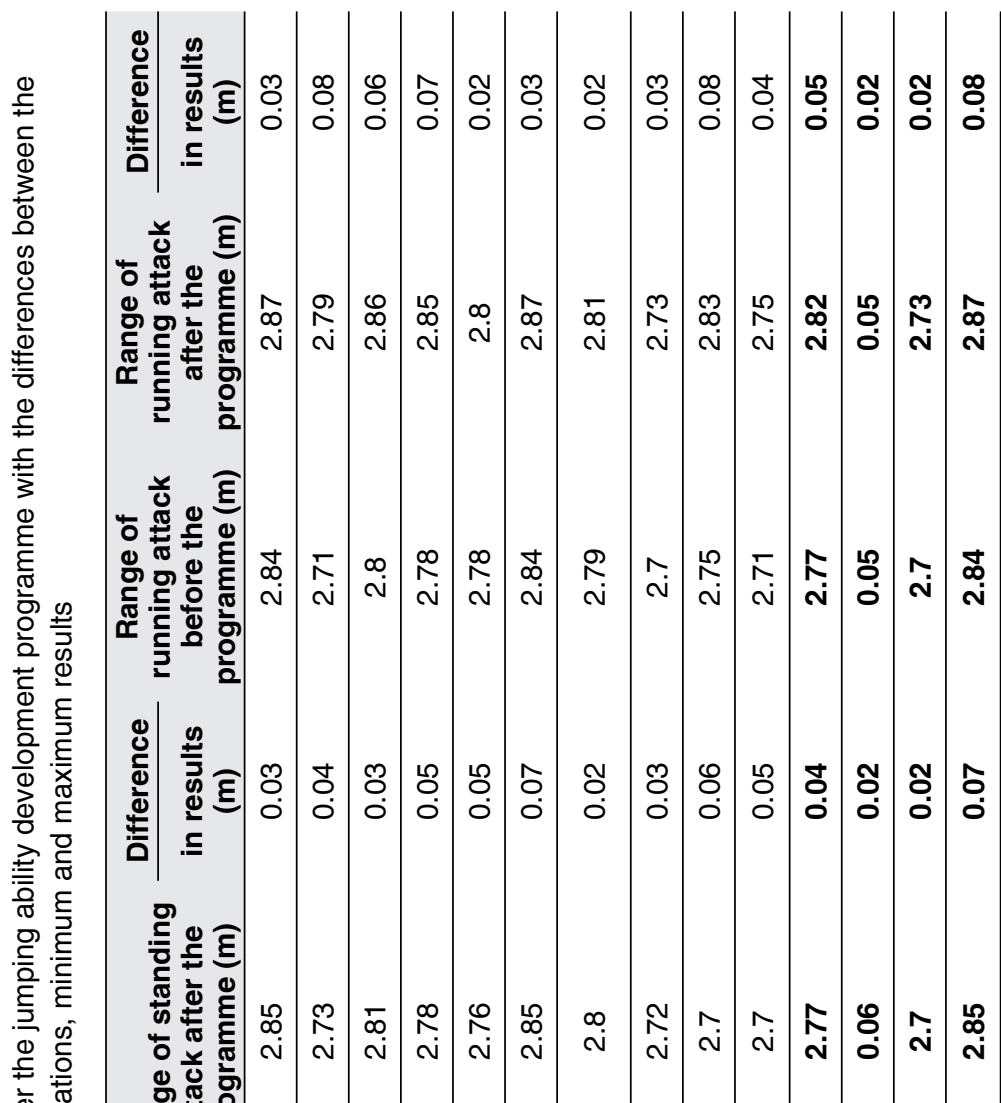
迹

은

(1) 응

능 $\frac{\text { त }}{4}$

姜

蛋

రั

क)

突范

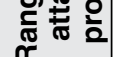

$\frac{\bar{\pi}}{\frac{0}{7}} \frac{0}{5}$

을 ฏ

등

के है

$\stackrel{0}{\stackrel{0}{(1)}}$

줌

ส ธิ

응 옳

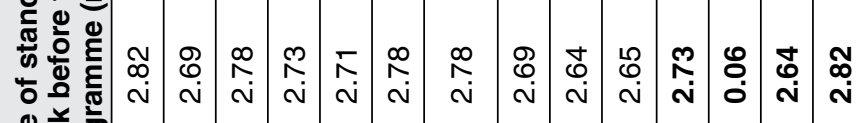
흥 흥

迅 百 은

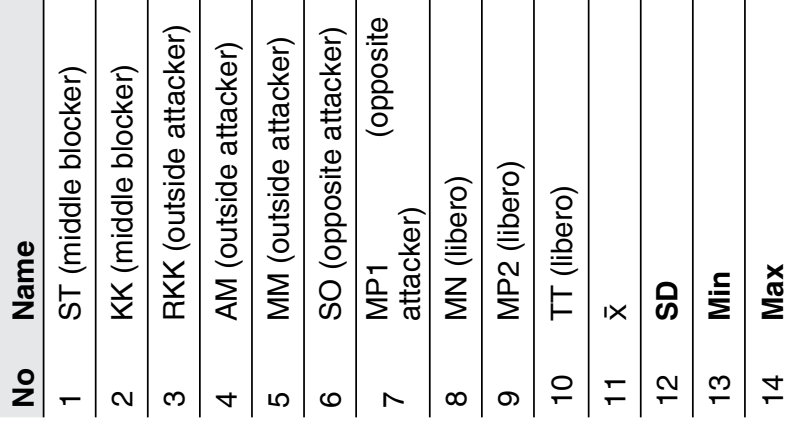


As for the running attack, the greatest development was shown by the libero player MP2 who jumped $8 \mathrm{~cm}$ higher after the jumping ability development programme. Still, the players SO and ST had the highest range of running attack - equally $2.87 \mathrm{~m}$ - which is $5 \mathrm{~cm}$ better than the team's mean. The smallest development was shown by the opposite attacker MP1 who showed only $2 \mathrm{~cm}$ of improvement after the programme. The lowest range of running attack was that of the libero $\mathrm{MN}$ whose result during the second assessment period was $2.73 \mathrm{~m}$. This was $9 \mathrm{~cm}$ less than the mean of the team (see Table 2).

To measure the differences between the first-time and second-time results of jumping height and range of attack, the $t$-test was applied.

We found statistically significant differences between the first-time and second-time results of both standing and running jump heights; the reliability coefficients were $\mathrm{p}=<0.0001$ and $\mathrm{p}=<0.0002$ respectively.

The range of the standing attack before the jumping development programme differed statistically significantly from the range after the programme; the reliability coefficient $\mathrm{p}=<0.0001$. The results of the running attack also differed statistically significantly before and after the programme $(\mathrm{p}=<0.0002)$.

While analysing the statistical indicators of games, it is essential to explain the difference between the terms efficiency and proficiency. While calculating the efficiency of attack, errors at attack are not taken into consideration. Efficiency only shows the percentage of sets that the player is able to hit to the ground. While calculating proficiency, errors are subtracted from the number of successful attacks.

Statistical indicators of performance in the game were analysed during two assessment periods. All the subjects played up to six games in the first period before the jumping ability development programme and up to six games in the second period after the jumping ability development programme. As for performance in the game, only one element - attack - was under observation in this study.

The analysis of the statistical indicators of the games showed that all the mean indicators of the team improved after taking the jumping ability development programme. The total number of attacks grew during the second assessment period. While the minimum number of attacks per player in the first assessment period was 9 , in the second assessment period it was 22 . The maximum number of sets per player in the first assessment period was 146; in the second assessment period it increased to 159 . The number of points scored increased by 0.8 points after the jumping ability development programme. 
While the minimum number of points scored per player in the first assessment period was 1 , in the second assessment period it was 8 . The maximum number of points scored increased by 5 after the jumping ability programme. Before the jumping ability programme the maximum number of points scored by a player was 52, after the programme it was 57. The number of points lost, however, decreased by 1.2 points on average. In the first assessment period the mean for the team was 13.3, in the second assessment period - 12.1. The efficiency and proficiency of attacks also improved after the jumping ability development programme. The team's mean efficiency of attack before the jumping ability development programme was $31.4 \%$. After the jumping ability development programme it rose to $36.0 \%$. The team's mean proficiency of attack in the first assessment period was $11.7 \%$. In the second assessment period, the mean result of the team was $18.3 \%$. While in the first assessment period, the minimum proficiency of the team was $-22 \%$; in the second assessment period, the proficiency of all the team members at attack was positive, and the minimum result was $1 \%$. Maximally improvement in the proficiency of attacks was 3\%. In the first assessment period, the team's maximum efficiency of attack was $29 \%$. In the second assessment period, the team's maximum proficiency of attack was $32 \%$ (see Table 3 ).

When the differences in proficiency and efficiency of attacks in the first and the second assessment periods were checked by the t-test, the differences did not prove to be statistically significant.

\section{DISCUSSION}

A. V. Belyayev and L. V. Bulykina's jumping ability development programme, which was originally meant to be used by male volleyballers, has already been used for developing young Estonian volleyballers, and very good results have been achieved $[4,5]$. After the 54-day training programme, the mean results of young volleyballers improved by 7 and $8 \mathrm{~cm}$. When the same jumping ability development programme was applied in the current study, the mean results of top female volleyballers also improved statistically significantly - by 4 and $5 \mathrm{~cm}$ respectively. Therefore, the programme can be recommended for other volleyballers as well.

The proficiency of attack also improved - the team's mean before the jumping ability development programme was $11.7 \%$, after it $-18.3 \%$. The number of points scored at attack also increased - 23.9 before and 24.7 afterwards - and the 


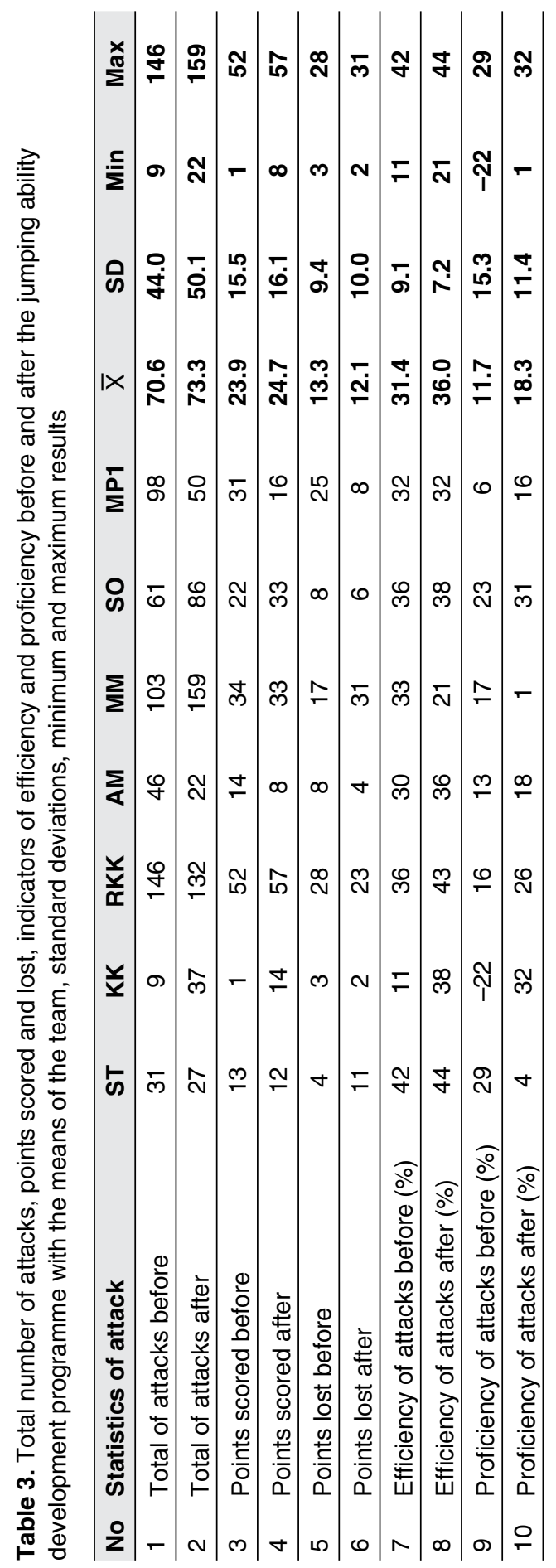


efficiency of attack improved - 31.4\% before and 36.0\% after the programme. The efficiency of attack improved in 5 players out of 7 and remained unchanged in one player; proficiency also increased in 5 players out of 7; the number of points scored at attack also increased, but the check by the t-test showed that the changes in the performance of attack were not statistically significant.

The greatest changes in the players' anthropometric measurements before and after the jumping ability development programme were revealed in weight and waist and hips circumferences, but the changes were not statistically significant.

\section{REFERENCES}

1. Belyayev A. V., Bulykina L. V. (2004). Theory and Practice of Physical Education, 3, 27-38.

2. Dopsaj M., Copic N., Nesic G., Sikimic M. (2012). Jumping performance in elite female volleyball players relative to playing positions: a practical multidimensional assessment model. Serbian Journal of Sport Sciences, 6 (2), 61-69.

3. Fattahi A., Ameli M., Sadeghi H., Mahmoodi B. (2012). Relationship between anthropometric parameters with vertical jump in male elite volleyball players due to game's position. Journal of Human Sport and Exercise, 7 (3), 714-726.

4. Sorgina N. (2011). Noorte võrkpallurite hüppevõime arendamine kahes erineva vanuse, soo ja kehaehitusega võrkpalli treeningrühmas. (Development of young volleyballers' jumping ability in two training groups with different age, sex and body build). (in Estonian) Master's thesis. Tallinn University.

5. Stamm R., Stamm M., Sorgina N., Koskel S. (2011). Training programme to develop young volleyballers' jumping ability. Papers on Anthropology XX, 380-388.

6. Tammerik S. (2013). Development of jumping ability and its influence on the proficiency of spike in the female volleyball team of Tallinn University in the 2012/2013 season. Bachelor's thesis. Tallinn University.

7. Volleyball Software, Stats version 6.3. (2012). Estonian Volleyball Federation.

8. Young W., MacDonald C., Heggen T., Fitzpatric J. (1997). An evaluation of the specificity, validity and realibility of jumping tests. J Sport MedPhys Fitness, 37, 240-245.

\section{Address for correspondence:}

Meelis Stamm

Institute of Educational Science

Tallinn University

Sireli 4, Tallinn, 10913, Estonia

E-mail: mella@tln.ee 